\title{
SODIUM BISULFITE AS AN EFFICIENT AND ECONOMICAL CATALYST FOR ONE-POT SYNTHESIS OF 2, 4, 5 TRISUBTITUTED IMIDAZOLES FROM BENZIL, AMMONIUM ACETATE AND AROMATIC ALDEHYDES BY MICROWAVE IRRADIATION
}

\author{
Arvind Tapase \\ Department of Chemistry, Abasaheb Marathe Arts and New Commerce, Science \\ College, Rajapur (Vikhare-Gothane) Dist. Ratnagiri 416702 \\ Email: arvindtapase@yahoo.com.
}

\begin{abstract}
:
Sodium Bisulfite is used as an efficient and economical catalyst for the synthesis of 2, 4, 5 triaryl $-\mathrm{H}$ imidazoles via condensation of benzil, ammonium acetate and aromatic aldehydes. The easy work-up, higher yields and shorter reaction time are the advantages of the method presented here.
\end{abstract}

Keywords: Triaryl imidazoles, benzil, ammonium acetate, aromatic aldehydes, Sodium Bisulfite, microwave irradiation.

\section{INTRODUCTION:}

Compounds with an imidazole ring system are biologically important due to their significant role in biochemical processes, as well as their use in synthetic chemistry ${ }^{1}$. An imidazole ring system is one of the most important substructures found in large number of natural products and pharmacologically active compounds e.g. amino acid, histidine and hypnotic agent etomidate ${ }^{2}$, and the proton pump inhibitor omeprazole ${ }^{3}$.

Trisubstituted imidazole derivatives are widely used as organic materials, such as to resist composition on textile, ${ }^{4}$ fluorescent whiteners on textile, 5 photographic materials, 6,7 electroluminescent materials ${ }^{8,9}$ and optical materials. ${ }^{10,11}$ Meantime, it was found that these compounds play roles in many kinds of biological activities. ${ }^{12,13}$ This versatile applicability highlights the importance of access to efficient synthetic routes to welldesigned and highly substituted imidazole derivatives. There are several methods for the synthesis of highly substituted imidazoles. ${ }^{14} \mathrm{~A}$ number of methods have been developed for the synthesis of 2,4,5-trisubstituted imidazoles. Which are generally synthesized by three component cyclocondensation of a 1,2diketone, a-hydroxy ketone with an aldehyde and ammonium acetate. It comprises the use of microwaves, ${ }^{15-18}$ ionic liquid, 19 refluxing in acetic acid,20-22 silica sulfuric acid,23-24 $\mathrm{NiCl}_{2} .6 \mathrm{H}_{2} \mathrm{O} / \mathrm{Al}_{2} \mathrm{O}_{3},{ }^{25} \quad \mathrm{Yb}(\mathrm{OTf})_{3},{ }^{26} \quad \mathrm{Yb}(\mathrm{OPf})_{3},{ }^{27}$ iodine, ${ }^{28} \quad \mathrm{Zr}$ (acac) ${ }_{4},{ }^{29} \quad \mathrm{InCl}_{3} .3 \mathrm{H}_{2} \mathrm{O},{ }^{30}$ heteropolyacid, ${ }^{31}$ potassium aluminium sulfate (alum), ${ }^{32}$ ceric ammonium nitrate (CAN), 33-34 polymer-supported $\mathrm{ZnCl}_{2}{ }^{35}$ and L-proline. ${ }^{36}$ Moreover, they have also been prepared by the addition of a substituted amino alcohol to a thioamide and subsequent oxidation with $\mathrm{PDC}^{37}$ or by the reaction of aryl nitriles and a, a-dilithio-arylnitromethanes ${ }^{38}$ or by multistep synthesis. ${ }^{39,40}$ Khodaei and co-workers in 2007 described the synthesis of 2,4,5-trisubstituted imidazoles from 1,2-diketone or ahydroxyketone, aldehyde and ammonium heptamolybdate tetrahydrate in tetrabutylammonium iodide using catalytic amount of $p$-TSA. ${ }^{41}$ Despite their potential utility, most of these synthetic methods suffer from one or more serious drawbacks, such as laborious and complex work-up and purification, significant amounts of waste materials, strongly acidic conditions, occurrence of side reactions, low yields, high temperature, long reaction time and the use of expensive reagents. In present work promote simple and efficient methods for one-pot synthesis of 2,4,5-trisubstituted imidazole derivatives starting from 1,2-diketone and various aromatic aldehydes under microwave conditions in the presence of sodium bisulfite as the catalyst.

\section{MATERIAL AND METHODS: Experimental}

All compounds were characterized by modern spectral and elemental techniques. IR spectra 
was recorded in $\mathrm{KBr}$ disc on a Perkin Elmer spectrometer for all products ${ }^{1} \mathrm{H}-\mathrm{NMR}$ spectra was recorded on NMR spectrometer in $\mathrm{CDCl}_{3}$ using chloroform as an internal standard. The mass spectra was recorded on GCMS-QP 2010 mass spectrometer. All the reagents used were of AR grade and were used without further purification. The reactions were carried out in microwave oven (CE2977 Samsung).

\section{General procedure for synthesis of 2, 4, 5 triaryl imidazoles}

A mixture of Benzil (10 mmol), ammonium acetate $(20 \mathrm{mmol})$, aldehyde $(10 \mathrm{mmol})$ and catalyst amount of Sodium Bisulfite $(2 \mathrm{mmol})$ were dissolved in $10 \mathrm{ml}$ ethanol in $50 \mathrm{ml}$ beaker, stirred for few seconds and placed in microwave oven for irradiation at 600 Watt for 105 to $145 \mathrm{sec}$. till completion of reaction was monitored by TLC. The reaction mixture was cooled to room temperature and poured in 50 $\mathrm{ml}$ ice-water to get the solid precipitate. It was collected by filtration, washed with water and dried to give crude product. The crude product was purified by crystallisation using ethanol as a solvent to obtain solid product of $2,4,5$ triaryl imidazole ( $1 \mathrm{a}$ to $1 \mathrm{k}$ ).

1a: 2, 4, 5 triaryl-1H- imidazole (M.P. 277$\left.278^{\circ} \mathrm{C}\right)$

IR (KBr): $3061(\mathrm{~N}-\mathrm{H}), 1600(\mathrm{C}=\mathrm{C}), 1488(\mathrm{C}=\mathrm{N})$, ${ }^{1} \mathrm{H}$ NMR $\left(400 \mathrm{Mz}, \mathrm{CDCl}_{3}\right): \delta=7.25-7.97(\mathrm{~m}$, $15 \mathrm{H} \mathrm{Ar}-\mathrm{H}), 8.15$ (brs, NH), ES-MS: $\mathrm{m} / z=297$ $(\mathrm{M}+1)$.

Anal. Cald for $\mathrm{C}_{12} \mathrm{H}_{16} \mathrm{~N}_{2}: \mathrm{C}, 85.11 ; \mathrm{H}, 5.44 ; \mathrm{N}$, 9.45 Found: C, 85.24; H,5.62; N,9.47

1b: 2(4- hydroxyphenyl) - 4, 5 - diphenyl 1H- imidazole (M. P. 267-268' C)

IR (KBr): $3215(\mathrm{~N}-\mathrm{H}), 1610(\mathrm{C}=\mathrm{C}), 1580(\mathrm{C}=\mathrm{N})$, ${ }^{1} \mathrm{H} \mathrm{NMR}\left(400 \mathrm{Mz}, \mathrm{CDCl}_{3}\right): \delta=6.75-6.60(\mathrm{~m}$, $15 \mathrm{H} \mathrm{Ar}-\mathrm{H}), 9.55$ (brs, NH), ES-MS: $\mathrm{m} / z=312$ $(\mathrm{M}+1)$.

Anal. Cald for $\mathrm{C}_{21} \mathrm{H}_{16} \mathrm{~N}_{2} \mathrm{O}: \mathrm{C}, 80.75 ; \mathrm{H}, 5.16 ; \mathrm{N}$, 8.97 Found: C, 80.78; H, 5.20; N, 8.99

1d: 2(4- Chlorophenyl) - 4, 5 - diphenyl - 1Himidazole (M. P. 261-262 ${ }^{\circ} \mathrm{C}$ )

IR (KBr): $3455(\mathrm{~N}-\mathrm{H}), 1620(\mathrm{C}=\mathrm{C}), 1582(\mathrm{C}=\mathrm{N})$, ${ }^{1} \mathrm{H} \mathrm{NMR}\left(400 \mathrm{Mz}, \mathrm{CDCl}_{3}\right)$ : $\delta=7.12-7.60(\mathrm{~m}$, $15 \mathrm{H} \mathrm{Ar}-\mathrm{H}), 7.355$ (brs, NH), ES-MS: m/z = 330 $(\mathrm{M}+1)$.

Anal. Cald for $\mathrm{C}_{21} \mathrm{H}_{15} \mathrm{ClN}_{2}$ : C, 75.25; $\mathrm{H}, 4.56$; N, 8.47 Found: C, 76.27; H, 4.58; N, 8.50

1e: 2(2- Chlorophenyl) - 4, 5 - diphenyl - 1Himidazole (M. P. $195-196^{\circ} \mathrm{C}$ )

IR (KBr): $3075(\mathrm{~N}-\mathrm{H}), 1582(\mathrm{C}=\mathrm{C}), 1492(\mathrm{C}=\mathrm{N})$, ${ }^{1} \mathrm{H} \mathrm{NMR}\left(400 \mathrm{Mz}, \mathrm{CDCl}_{3}\right): \delta=7.7-7.66(\mathrm{~m}, 6 \mathrm{H}$ Ar - H), $7.68-7.70(\mathrm{~m}, 2 \mathrm{H}), 7.8-8.2$ (brs, NH), ES-MS: $\mathrm{m} / \mathrm{z}=330(\mathrm{M}+1)$.
Anal. Cald for $\mathrm{C}_{21} \mathrm{H}_{15} \mathrm{ClN}_{2}$ : C, 76.25; H, 4.57;

N, 8.47 Found: C, 76.26; H, 4.57; N, 8.52

\section{Reaction}

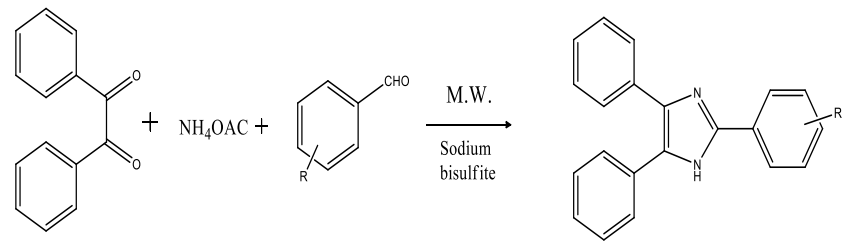

1, 2-diketone Ammonium Aromatic

2, 4, 5 - triaryl imidazole

Acetate aldehyde

\section{RESULTS AND DISCUSSION:}

In order to find optimum reaction conditions, condensation of benzil, benzaldehyde and ammonium acetate in the presence of sodium bisulfite as catalyst was done. The optimum molar ratio of benzil: benzaldehyde: ammonium acetate 1:2:1 and sodium bisulfite $(2 \mathrm{~mol} \%)$ using ethanol solvent under microwave irradiation, 2(phenyl) 4, 5- diphenyl $1 \mathrm{H}$ - imidazole was obtained with $97 \%$ yield at 600 Watt for 118 Sec. Results with benzaldehydes were encouraging in a similar fashion, a variety of aromatic and heterocyclic aldehyde and benzil subjected to this microwave assisted procedure gives high yields of corresponding 2, 4, 5 triaryl imidazole. The results are summarized in Table1. From the results mentioned in Table the aldehyde with electron-donating substituents favour the reaction and it was completed with shorter reaction time and high yields than the aldehyde with electron-withdrawing substituents. Also, the present method was found to be effective for hetero-aromatic aldehyde for the synthesis of 2-heteroaryl 4, 5 diphenyl 1 Himidazole with better yield. To determine the role of sodium bisulfite the same reaction was carried out in the absence of catalyst at same conditions, which resulted in no product formation after $15 \mathrm{~min}$. these result indicate that sodium bisulfite exhibits a high catalytic activity in this transformation. The procedure gives high yield products.

Comparison of results as mentioned in Table- 1 with results obtained by some other reported procedures for synthesis of 2, 4, 5 triaryl imidazoles shows the promising feature of this method in terms of reaction rate and the yield of products as compared with reports in the literature. 


\section{CONCLUSION}

In conclusion, we presented an efficient, mild and rapid approach for the synthesis of 2,4,5 trisubstituted imidazoles via condensation of a representative 1,2-diketone (Benzil) with various aromatic aldehydes and ammonium acetate, by using sodium bisulfite as an efficient and inexpensive catalyst under microwave irradiation. Non-corrosiveness, safe, low waste, easy for separation, short time, high yields and environmentally benign are some of the advantages of this methodology.

\section{ACKNOWLEDGEMENT}

The author are thankful to the Principal, Abasaheb Marathe Arts and New Commerce, Science College, Rajapur Dist. Ratnagiri for providing necessary facilities.

\section{REFERENCE:}

Philips A. P. White H. L and Rosen S. E., 1982, Appl E P 58890.

Wanguier A., VanDen Broeck W. A. E., Verheyen J. L. and Janen P. A. 1978, J. Janen, Eur. J. Pharma., 47 ,367.

Tanigawara Y., Aoyama N., Kita T., Shirakawa K., Komada F., Kasuga M. and Okumura K., 1999, Clin. Pharmacol R Ther. 66, 528.

Watanabe T, Kinsho T and Hasegawa K 2004,US $234884 \mathrm{~A} 1$.

Siegrist A, Liechti P and Meyer H R 1973, CH 542 266.

Etou K, Nanhei M and Tanaka S 1983, US 440 5705.

Meji I and Fukui M 1995, JP 07005628 A2.

Dodabalapur A, Strukelj M and Jordan R 1997, EP 763965 A2.

Mataka S and Hatta T 2005, WO 085208 A1.

Gostev F E, Kol'tsova L S, Petrukhin A N, Titov A A, Shiyonok A I and Zaichenko N L 2003, J. Photochem. Photobiol. A. Chem.156, 15.

Park S, Kwon O H and Kim S 2005, J. Am. Chem. Soc. 127, 10070.

Lee J C, Laydon J T and Mcdonnell P C 1994, Nature 372, 739.

Lombardino J G 1972 DE 2155558 [1973 US 3 772 441].

Grimmet M R A R Katritzky and C W Rees 1984 in Comprehensive heterocyclic chemistry (eds) (London: Pergamon Press) vol. 5, p. 374.

Usyatinsky A Y and Khemelnitsky Y L 2000 Tetrahedron Lett. 415031.

Wolkenberg S E, Wisnoski D D, Leister W H, Wang Y, Zhao Z and Lindsley C W 2004 Org. Lett. 6, 1453.
Sparks R B and Combs A P 2004, Org. Lett. 6,2473.

Oskooie H A, Alimohammadi Z and Heravi M M 2006, Heteroatom Chem. 17, 699.

Khosropour A R 2008, Can. J. Chem. 86, 264.

Wang J, Mason R, Derveer D V, Feng K and Bu X R 2003, J. Org. Chem. 68, 5415.

Sarshar S, Siev D and Mjalli M M 1996, Tetrahedron Lett. 37, 835.

Gallagher T F, Seibel G L, Kassis S and Laydon J T 1997, Bioorg. Med. Chem. 5, 49.

Shaabani A and Rahmati A 2006, J. Mol. Catal. A: Chem. 249, 246.

Shaabani A, Rahmati A, Farhangi E and Badri Z 2007, Catal. Commun. 8,1149.

Heravi M M, Bakhtiari K, Oskooje H A and Taheri S 2007, J. Mol. Catal. A: Chem. 263, 279.

Wang L, Wang Y, Tian H, Yao Y, Shao J and Liu B 2006, J. Fluorine. Chem. 127, 1570.

Shen M, Cai C and Yi W 2008, J. Fluorine. Chem. $\mathbf{1 2 9}, 541$.

Kidwai M, Mothsra P, Bansal V, Somvanshi R K, Ethayathulla A S, Dey S and Singh T P 2007, J. Mol. Catal. A: Chem. 265, 177.

Khosropour A R 2008, Ultrason. Sonochem. 15, 659.

Sharma S D, Hazarika P and Konwar D 2008, Tetrahedron Lett. 49, 2216.

Heravi M M, Sadjadi S, Oskooje H A, Hekmatshoar $\mathrm{R}$ and Bamoharram F F 2008, J. Chin. Chem. Soc. 55, 1199.

Mohamadi A A, Mivechi M and Kefayati H 2008, Monatsh. Chem. 139, 935.

Sangshetti J N, Kokare N D, Kotharkar S A and Shinde D B 2008, J. Chem. Sci. 120, 463.

Shaabani A, Maleki A and Behnam M 2009, Synth. Commun. 39, 102.

Wang L and Cai C 2009, Monatsh Chem. 140, 541.

Sami S, Nandi G C, Singh P and Singh M S 2009, Tetrahedron 65, 10155.

Paone D Vand Shaw A W 2008, Tetrahedron Lett. 49, 6155.

Hayes J F, Mitchel M B and Wicks C 1994, Heterocyclic 38, 575.

Revesz L, Bonne F and Makavou P 1998, Tetrahedron Lett. 39, 5171.

Liverton N J, Butcher J W, Claiborne C F and Claremon D A 1999, J. Med. Chem. 42, 2180.

Khodaei M M, Bahrami K and Kavianinia I 2007, J. Chin. Chem. Soc. 54, 829. 
Table - 1 - Physical data of the synthesized compounds

\begin{tabular}{|c|c|c|c|c|c|c|}
\hline $\begin{array}{l}\text { Ent } \\
\text { ry }\end{array}$ & Aldehyde & $\begin{array}{c}\text { Watt } \\
\text { W }\end{array}$ & $\begin{array}{l}\text { Time } \\
\text { Sec. }\end{array}$ & $\begin{array}{c}\text { Yield } \\
(\%)\end{array}$ & $\begin{array}{l}\text { M. P. }\left({ }^{\circ} \mathrm{C}\right) \\
\text { Found }\end{array}$ & $\begin{array}{l}\text { M. P. }\left({ }^{\circ} \mathrm{C}\right) \\
\text { Reported }\end{array}$ \\
\hline $1 \mathrm{a}$ & Benzaldehyde & 600 & 118 & 97 & $277-278$ & $276-277^{14}$ \\
\hline $1 \mathrm{~b}$ & 4-OH- Benzaldehyde & 600 & 125 & 93 & $267-268$ & $268-269^{33}$ \\
\hline $1 \mathrm{c}$ & 4- $\mathrm{CH}_{3}-$ Benzaldehyde & 600 & 130 & 95 & $231-233$ & $231-232^{33}$ \\
\hline $1 d$ & 4-Cl- Benzaldehyde & 600 & 120 & 96 & $261-262$ & $261-263^{33}$ \\
\hline $1 \mathrm{e}$ & 2-Cl- Benzaldehyde & 600 & 115 & 94 & 195-196 & $197-198^{33}$ \\
\hline 1f & 4-N(CH 3$)_{2}-$ Benzaldehyde & 600 & 105 & 94 & $256-257$ & $257-258^{33}$ \\
\hline $1 \mathrm{~g}$ & 4- $\mathrm{NO}_{2}$ - Benzaldehyde & 600 & 128 & 91 & $234-236$ & $236-238^{33}$ \\
\hline $1 \mathrm{~h}$ & 3,4-($\left(\mathrm{OCH}_{3}\right)_{2}-$ Benzaldehyde & 600 & 118 & 95 & $220-221$ & $216-218^{33}$ \\
\hline $1 \mathrm{i}$ & 4-OCH${ }_{3}-$ Benzaldehyde & 600 & 130 & 93 & $228-230$ & $227-228^{33}$ \\
\hline $1 \mathrm{j}$ & 4-Br- Benzaldehyde & 600 & 145 & 94 & $264-265$ & $261-263^{33}$ \\
\hline $1 \mathrm{k}$ & 2-Furan & 600 & 128 & 95 & $202-203$ & $202-203^{26}$ \\
\hline
\end{tabular}

